\title{
Harm Reduction: When Evidence Should Influence Health Policy
}

Bikaramjit Mann MD

\begin{abstract}
About the Author
Bikaramjit Mann is an internal medicine resident (PGY-2) at the University of Calgary, in Calgary, Alberta. Correspondence may be directed to mannb@ucalgary.ca.
\end{abstract}

\section{Summary}

Harm reduction can be thought of as any program or policy designed to reduce drug-related harm without requiring the cessation of drug use. An example of a successful harm reduction strategy is the use of needle exchange programs or syringe exchange programs. Unfortunately, decisions may be made by policy makers that conflict with scientific literature and the abundance of evidence supporting such harm reduction measures. Evidence in favour of harm reduction strategies is robust, and their implementation is required in any comprehensive public health policy attempting to improve the well-being of society as a whole. This article examines the evidence supporting the efficacy of one such harm reduction strategy, namely, needle exchange programs; it also outlines a simple approach for medical students, residents, physicians, and other health care professionals to be involved in change on a global scale by discussing the Vienna Declaration as a tool for influencing evidence-based drug policy.

\section{Résumé}

Le programme ou la politique dont l'objectif consiste à réduire les méfaits ou les conséquences de la consommation de drogues illicites sans pour autant passer par l'arrêt de cette consommation ou la prohibition des drogues constitue une stratégie de réduction des méfaits ou des conséquences de l'utilisation de drogues. À titre d'exemple de réussite en cette matière, citons le programme d'échange de seringues ou d'aiguilles. Malheureusement, les décisions des responsables des orientations politiques vont parfois à l'encontre de la recherche scientifique et des données probantes abondantes qui appuient le bien-fondé des mesures de réduction des conséquences de la consommation de drogues. Les faits qui justifient la stratégie de réduction des méfaits sont solides, et ils devraient être mis en application dans le cadre de tout programme de santé publique destiné à améliorer le bien-être de la société dans son ensemble. L'article passe en revue les données probantes démontrant l'efficacité d'une telle stratégie, plus précisément du programme d'échange d'aiguilles; il invite les étudiants en médecine, les médecins résidents, les médecins et les autres professionnels de la santé à participer à l'instauration d'un changement à l'échelle mondiale en se servant de la Déclaration de Vienne pour favoriser l'élaboration de politiques et de programmes fondés sur des données probantes. 
$\mathrm{T}$ here are moments in each of our lives that have the potential to change our personal philosophies and outlook. In my third year of medical school, I met an exceptional chief resident who had a large influence on my decision to enter internal medicine. During one teaching session, I learned there was compelling evidence for harm reduction and that the evidence that existed was at least as abundant as that for global warming. A powerful statement, and one that provided food for thought as I progressed through my clerkship. As a resident, I have started examining the evidence for myself, confirming his perspective.

Harm reduction can be thought of as any program or policy designed to reduce drug-related harm without requiring the cessation of drug use. One such harm reduction strategy is the use of needle exchange programs (NEPs) or syringe exchange programs (SEPs). NEPs attempt to reduce human immunodeficiency virus (HIV) transmission among injection drug users (IDUs) by providing clean needles in exchange for used ones. It has been demonstrated that cities without NEPs have an increased incidence of HIV transmission when compared with cities that utilize NEPs. ${ }^{1}$ These programs appear to reduce the incidence of HIV in a variety of settings and may be due to several behavioural factors, such as needle sharing, lending, or borrowing. ${ }^{2}$

Despite the evidence to support the benefits of NEPs, there are still those who oppose their implementation from a drugpolicy perspective. One example that has been cited was the increased rate of HIV infection in Montreal's NEP program, ${ }^{3}$ a statistic contrary to the assertions of benefit in sizeable literature. Furthermore, much of the political opposition to NEPs has been fueled by an early evaluation of NEPs and HIV prevalence in Vancouver. ${ }^{4}$ The higher HIV prevalence reported by weekly NEP users was later explained by the fact that these users were more likely to be high-risk IDUs, compared with less frequent users. ${ }^{5}$

A recent study has demonstrated the power that modifications to drug policy may provide. ${ }^{6}$ Many IDUs find it difficult to obtain sterile syringes as a result of policy and programmatic factors, such as limited hours of NEP operation, and a rigid one-for-one syringe exchange policy. Between 2000 and 2002, the health authority in Vancouver changed its focus on syringe exchange to syringe distribution. Authors studying this program found that by increasing access to clean syringes and separating syringe distribution from collection, there was a reduction in syringe borrowing and syringe lending, as well as a decline in the incidence of HIV infection. ${ }^{7,8}$

My brief overview of the literature surrounding NEPs, and the concept of harm reduction, convinces me that harm reduction programs such as NEPs are beneficial for the public at large. When I entered medical school, I had little appreciation for global health: I believed there were plenty of issues that required attention in my local community. Injection drug use, HIV, and harm reduction highlight a local issue with global implications - arguably better than any other example that comes to mind. Addiction plagues countries around the world, both in developed and developing nations, and any comprehensive public health policy should include harm reduction strategies. As I encountered patients who suffered from addiction, I began to appreciate the hardships faced by individuals in our local and global communities.

We should strive to provide drug-addicted individuals with every opportunity to break their habit, regardless of their socioeconomic or ethnic backgrounds. Addiction has, however, multiple bio-psychosocial complexities. For example, the drug users must be at the preparation and action stages for any drug cessation program to be potentially successful. Until they reach these stages, we should help to reduce the potential for harm such individuals might bring upon themselves or others, particularly when they are still in the pre-contemplation or contemplation stages of change.

The aforementioned chief resident, who initially sparked my interest in harm reduction and global health, is Evan Wood, one of the authors of the Vienna Declaration. As health care professionals, we may ask ourselves how we can impact public health and policy and aid the global community, without necessarily entering politics or full-time health care research. A starting point may be to sign the Vienna Declaration, a document unveiled on World AIDS Day in 2010 by the International AIDS Society (www.viennadeclaration.com/). More than 20,000 individuals have already done so. The declaration aims to improve community health and safety by calling for the incorporation of scientific evidence into illicit-drug policies so that policy is influenced by evidence, not ideology. Nobel laureates, scientists, physicians, members of the public - and cities such as Vancouver, Victoria, and Toronto - have endorsed the declaration. Many of us would like to contribute to change on a larger scale, but this initiative provides a unique forum for physicians and others to direct policy on a global scale. I echo the words of Dr. Elly Katabira, president of the International AIDS Society, who stated, "We will no longer accept misguided policies."

As physicians, I believe we have an incredible opportunity to affect individual patients' lives, both in our local and global communities. According to the most recent Canadian Collaborative Centre for Physician Resources National Physician Survey, Canada has over 70,000 physicians. I'm sure that many of them, and other health care professionals, will share my views. I would encourage my colleagues to take part in this important 
initiative, and to embrace evidence-based decisions in drug policy by signing the Vienna Declaration.

\section{References}

1. Hurley SF, Jolley DJ, Kaldor JM. Effectiveness of needle-exchange programmes for prevention of HIV infection. Lancet 1997;349:1797-800.

2. Ksobiech K. A meta-analysis of needle sharing, lending, and borrowing behaviors of needle exchange program attenders. AIDS Ed Prevent 2003;15:257-68.

3. Brumeau J, Lamonthe F, Franco E, et al. High rates of HIV infection among injection drug users participating in needle exchange programs in Montreal: results of a cohort study. Am J Epidemiol 1997;146:994-1002.

4. Strathdee SA, Patrick DM, Currie SL, et al. Needle exchange is not enough: lessons from the Vancouver injecting drug use study. AIDS 1997;11:F59-F65.

5. Schechter MT, Strathdee SA, Cornelisse PGA, et al. Do needle exchange programmes increase the spread of HIV among injection drug users? An investigation of the Vancouver outbreak. AIDS 1999;13:F45-51.

6. Kerr T, Small W, Buchner C, et al. Syringe sharing and HIV incidence among injection drug users and increased access to sterile syringes. Am J Public Health 2010;100:1449-53.

7. Wood E, Tyndall MW, Spittal PM, et al. Factors associated with persistent high-risk syringe sharing in the presence of an established needle exchange programme. AIDS 2002;16:941-3.

8. Wood E, Tyndall MW, Spittal P, et al. Needle exchange and difficulty with needle access during an ongoing HIV epidemic. Int J Drug Policy 2002;13:95102.

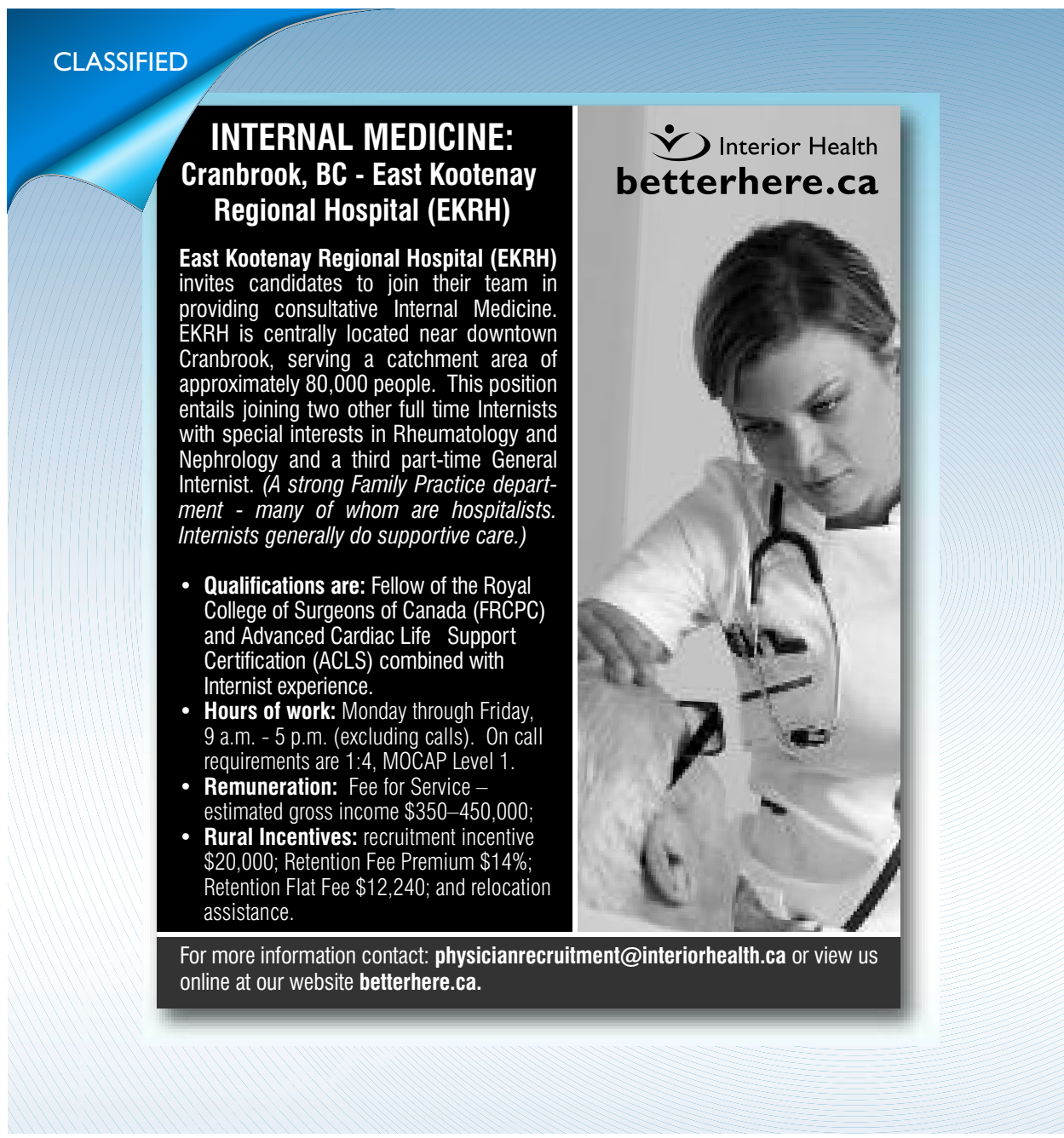

